able amounts of blood loss. The total length of menstrual bleeding and the amount (number of tampons used) was reduced in all cases. One patient noted some intermenstrual spotting, but this was acceptable.

The first two patients have been followed up for 11 and 16 months respectively and are alive and well, still with regular menstrua cycles and acceptable blood loss. The third patient was followed up for seven months and during this time had regular cycles with no side effects; four months after insertion she had a kidney transplant and three months later died from a massive gastrointestinal haemorrhage. The fourth patient was seen for nine months after IUD insertion; after five months she also had a kidney transplant and four months later died from pneumococcal pneumonia. These two deaths were not related to the IUD use.

We conclude from this small series that the progesterone IUD offers definite advantages for patients undergoing haemodialysis who have heavy periods. In contrast to the use of systemic steroids intrauterine progesterone produces regular cycles with acceptable menstrual blood loss.

J NewTON S A SNOWDEN VICTOR PARSONS

Department of Obstetrics and

Gynaecology,
King's College Hospital Medical School,

King's Colleg

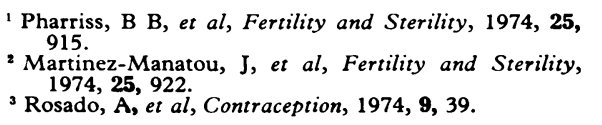

${ }^{3}$ Rosado, A, et al, Contraception, 1974, 9, 39.

\section{Laparoscopic removal of IUDs from the} abdomen

SIR,-Perforation of the uterine wall by intrauterine contraceptive devices (IUDs) is an uncommon but not rare occurrence. With the increasing popularity of the IUD the incidence of this complication will quite possibly increase.

We have recently seen two such cases. Both presented with diffuse acute low abdominal pain which had started three or four days after insertion of an IUD (Lippes loop, size $\mathrm{C}$, in one and Copper-7 (Gravigard) in the other) by an experienced general practitioner. The pain had gradually become more severe over five or six days until admission. Both patients were multiparous and apparently had normal pelvic anatomy at insertion of the IUD. On examination there was generalised lower abdominal tenderness and marked cervical excitation. The thread of the IUD could be neither seen nor felt in the cervix.

Removal was by laparoscope, using a method basically similar to that described by Steptoe, ${ }^{1}$ under general anaesthesia. The thread attached to the IUD was in both cases visualised by manipulation of the uterus by means of Hulka forceps in the cervix. The thread was then grasped with Palmer forceps passed into the abdomen through a trocar inserted at the junction of the medial third and the lateral two-thirds of a line joining the umbilicus and right anterior superior iliac spine. The forceps and trocar were then withdrawn together, and the IUD, still grasped by its thread with the forceps, was manipulated through the tiny incision made by insertion of the trocar. In both cases the site on the posterior aspect of the uterus at which perforation had occurred was scarcely noticeable. The only other pathological finding in the abdomen was a pool of "old" blood, about $20-30 \mathrm{ml}$ in volume, in the pouch of Douglas. In both cases the patient was able to be discharged the following day.

These cases illustrate the use of laparoscopy as a therapeutic as well as diagnostic process and also emphasise the importance of checking the position of the IUD in patients presenting with low abdominal pain who have had one of these devices fitted.

West Kent General Hospital,

Derek J Pearce Maidstone

Steptoe, P C, Laparascopy in Gynaecology, 2nd edn Edinburgh, Livingstone, 1975.

\section{IUDs and fibrinolysis}

SIR,-In your leading article ( 7 February, p 304) you suggest that the mechanism of the tendency of intrauterine contraceptive devices (IUDs) to cause heavy periods might not be completely separable from the mechanism of the device's contraceptive action.

We examined fertilised rat ova histochemically for their fibrinolytic activity. ${ }^{1}$ Activity was found during tubal passage but disappeared at implantation. Simultaneously the fibrinolytic activity of the endometrium disappeared. It is well known that inhibition of fibrinolysis in organ and cell culture on clotted substrates promotes adhesion and growth. ${ }^{2}$ Absence of fibrinolytic activity might thus be a prerequisite for implantation of the zygote. In the light of these observations it is of interest to note that IUDs raise the fibrinolytic activity in the endometrium, which, in contrast to that of non-users, is localised to the superficial cell layer."

The disappearance of endometrial fibrinolytic activity at the time of decidualisation prompted us to study the human decidua in tissue culture for inhibitors of fibrinolysis. We used a method in which tissue explants are cultured in the presence of, but not in contact with, a preformed standard plasminogen-contaminated fibrin clot. Urokinase added to the culture medium degrades the fibrin with consequent accumulation of stable fibrin degradation products (FDP) in the medium. The amount of FDP is assessed immunochemically. When inhibitors are released from the cultured explants they will inhibit the formation of FDP. ${ }^{4}$ The results are given in the table.

Inhibition of urokinase by decidua in organ culture. Mean value of two cultures. Each value denotes FDP content in $\mu \mathrm{g} / \mathrm{l}$ of Parker medium

\begin{tabular}{|c|c|c|c|}
\hline & \multicolumn{3}{|c|}{ Days of culture } \\
\hline & 1 & 2 & 3 \\
\hline 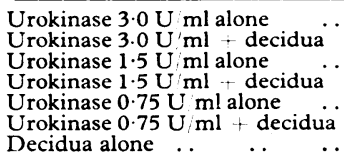 & $\begin{array}{l}153 \\
15 \\
27 \\
7 \\
1 \cdot 5 \\
0 \\
0\end{array}$ & $\begin{array}{r}228 \\
69 \\
87 \\
22 \\
15 \\
0 \\
0\end{array}$ & $\begin{array}{l}448 \\
120 \\
195 \\
38 \\
60 \\
5 \\
1.5\end{array}$ \\
\hline
\end{tabular}

We also examined decidua cultures for their influence on the fibrinolytic activity of rat ova. When rat ova were incubated on fibrin slides without culture medium or with addition of fresh medium the mean lytic area was found to be $90 \times 10^{3} \mu \mathrm{m}^{2}$. On the slides to which human or rat decidua culture medium had been added to the fibrin film the lytic area never exceeded the area of the ovum-that is, $<18 \times 10^{3}$ : $\mathrm{m}^{2}$.

IUDs medicated with inhibitors of fibrinolysis have been claimed to decrease the incidence of intermenstrual bleeding as well as heavy periods. However, the possible inter- ference of such treatment with the contraceptive effect of the device should be borne in mind.

B ÅsTedT

Department of Obstetrics and $P$ LIEDHOLM Gynaecology,
University of Lund,
Allmänna Sjukhuset,
Malmö, Sweden

${ }^{1}$ Liedholm, P, and Åstedt, B, International Journal of

Fertility, $1975,20,24$.
Ingemanson-Nordqvist, B, and Källén, B, Experimerital Cell Research, 1961, 21, 232.
Larsson, B, Liedholm, $\mathrm{P}$, and Astedt, Larsson, B, Liedholm, P, and Astedt, B, International
Journal of Fertility, 1975, 20, 77.
Astedt, B, Pandolf, M, and Nilsson, I M, Proceedings

of the Society for Experimental Biology and Medicing $1972,139,1421$.

\section{Supervision of repeat prescribing}

SIR,-As director of the research centre from which the paper by Mrs S M Shaw and $M r$ L J Opit comes I am naturally distressed at the astonishment, hilarity, and anger of the practitioners involved (20 March, p 713). The authors themselves are, of course, responsible for the views expressed in the paper and I would not wish to speak for them, but I think I must in fairness reply on behalf of a number of other loyal and hardworking collaborators and say how much I regret unwarranted public castigation of their work.

I appreciate that these comments arise from the hot sense of injustice which the partners feel, and this partly from their failure to receive their transcript of the paper. We suppose this error must have occurred in this office and must accept responsibility, although we are now unable to trace events because of a burglary with much destruction and subsequent disorganisation. Absence of acknowledgements in the paper was due to the partners' request for non-identification following their perusal and commentary upon earlier accounts of the work and not to any intended slight.

There is one other point I must put straight. It is possible to read one of the sentences in the partners' letter to imply that Mrs Shaw changed the treatment of one of the patients. This was raised in discussion between ourselves and the practice, when I was present, and it was explained that a locum doctor changed the treatment when informed of the situation. This was not doubted by the partners at the time and I hope they are not doubting it now. Perhaps I am over-sensitive in treating a bit of ambiguous English as something which could be seen as an innuendo.

E G KNox

Health Services Research Centre,

University of Birmingham

\section{Disposable bacteriological loops and} vaginal discharge

SIR,-The investigation of a vaginal discharge involves sample taking from the urethra, cervix, and vagina for Gram staining, culture, and wet-film microscopy. The standard bacteriological swab has certain drawbacks. It is too big to enter the urethra without pain and may be too big to enter the cervical canal. Any Gram films made may be obscured by carbon particles if a charcoal-coated swab is used. A common alternative is the platinum 